\title{
Hydrocephalus treatment in children: long-term outcome in 975 consecutive patients
}

\author{
Pierre-Aurelien Beuriat, MD, ${ }^{1}$ Stephanie Puget, MD, PhD, ${ }^{2}$ Giuseppe Cinalli, MD, ${ }^{3}$ \\ Thomas Blauwblomme, MD, ${ }^{2}$ Kevin Beccaria, MD, ${ }^{2}$ Michel Zerah, MD, PhD, ${ }^{2}$ and \\ Christian Sainte-Rose, MD, PhD²
}

\begin{abstract}
${ }^{1}$ Department of Pediatric Neurosurgery, Hôpital Femme Mère Enfant, Lyon Cedex; 2 Department of Pediatric Neurosurgery, Hôpital Necker-Enfants Malades, Paris, France; and 'Department of Pediatric Neurosurgery, Santobono-Pausilipon Children's Hospital, Napoli, Italy
\end{abstract}

\begin{abstract}
OBJECTIVE Hydrocephalus remains one of the more common pathologies managed in pediatric neurosurgical units. Endoscopic third ventriculostomy (ETV) has an advantage over ventriculoperitoneal shunting as it enables patients to remain device free. Multiple shunt devices with various valve designs exist, with no one valve proven to be superior to another. The aim of this study was to describe the management of hydrocephalus and its long-term outcome.
\end{abstract}

METHODS The authors retrospectively reviewed the medical records of all patients who had been treated for hydrocephalus at the Hôpital Necker-Enfants Malades in the period from 1985 to 1995.

RESULTS Nine hundred seventy-five children had been treated for hydrocephalus. The mean follow-up was $11 \pm 7.4$ years (mean \pm standard deviation). The most common cause of hydrocephalus was tumor related (32.3\%), followed by malformative $(24.5 \%)$ and inflammatory $(20.9 \%)$ causes. Two hundred eighty patients underwent ETV as the first-line treatment. The procedure was effective in controlling hydrocephalus due to posterior fossa tumors and aqueductal stenosis. Six hundred ninety-five children had initial shunt insertion, with the majority receiving an Orbis-Sigma valve (OSV). The overall OSV shunt survival was $70 \%$ at 1 year, $58 \%$ at 10 years, and $49 \%$ at 20 years. The most common cause for mechanical shunt failure was obstruction $(50.7 \%)$. Overall shunt survival was statistically different between the OSV and the differential-pressure valve $(p=0.009)$.

CONCLUSIONS Endoscopic third ventriculostomy is effective in the management of childhood hydrocephalus. Its success is directly related to the underlying pathology. In the long term, the OSV has significantly higher event-free shunt survival than the classic differential-pressure valve systems

https://thejns.org/doi/abs/10.3171/2017.2.PEDS16491

KEY WORDS hydrocephalus; pediatric; ventriculoperitoneal shunt; complications

$\mathrm{H}$ YDROCEPHALUS remains one of the more common pathologies managed in pediatric neurosurgical units with endoscopic third ventriculostomy (ETV) and ventriculoperitoneal shunt (VPS) insertion the mainstays of treatment. Endoscopic third ventriculostomy has an advantage over VPS insertion as it enables patients to remain device free. However, its efficacy, even now, is widely discussed in the literature. ${ }^{9}$ Ventriculoperitoneal shunting, the more conventional treatment, has undergone many advances since its inception in the mid-1950s. ${ }^{26}$ Yet this shunt remains a high-risk device, ${ }^{6}$ with shunt failure a significant cause of morbidity. ${ }^{3}$ Currently, multiple shunt devices with various valve designs exist, ${ }^{2}$ with no one valve proven to be superior to another. ${ }^{26}$ Multiple studies have examined shunt survival for almost every kind of shunt that is commonly used, , ,7,8,10-12,14,15,18-20,22-25,31 but the patient numbers for most of these studies were low or the length of follow-up was short.

ABBREVIATIONS DP = differential pressure; ETV = endoscopic third ventriculostomy; OSV = Orbis-Sigma valve; VAS = ventriculoatrial shunt; VPS = ventriculoperitoneal shunt. 
To address these issues, we retrospectively reviewed all patients who had been treated for hydrocephalus at the Hôpital Necker-Enfants Malades in the period from 1985 to 1995 with the aim of describing the management of hydrocephalus and its long-term outcome.

\section{Methods \\ Study Design}

All patients who had undergone an initial procedure at the Hôpital Necker-Enfants Malades for the management of hydrocephalus between 1985 and 1995 were included in this study. We chose these periods of study (1985-1995) and analysis (2014-2015) to get a follow-up range covering the entire "pediatric period" (that is, 20 years). Patient data were obtained through a retrospective review of the medical records. Follow-up data were obtained from the last outpatient consultation or via a telephone call with the patient or parents, the general practitioner, or the neurosurgeon who continued the long-term care, whichever was later.

\section{Definitions}

For the purpose of this study, we defined failure of ETV as when a patient needed another surgical procedure (either repeat ETV or shunt insertion) for the adequate control of hydrocephalus. The decision to perform the surgery was made when a patient presented clinical signs of raised intracranial pressure with ventricular enlargement as compared with the ventricular appearance on a reference image (that is, the last brain image when the patient was doing well).

Shunt failure was defined as when a patient underwent any additional hydrocephalus-related surgery following the initial implantation. Shunt infection was defined as a positive shunt or CSF culture requiring removal and replacement of the shunt system and antibiotic therapy.

\section{Data Collection}

Collected data included patient sex, gestational age, weight at birth, age at first procedure, etiology of hydrocephalus, and vital status. Etiology was categorized as inflammatory (postinfectious, posthemorrhagic, posttraumatic), malformative (spina bifida, Chiari malformation), aqueductal (aqueductal stenosis), tumoral, and other. We noted the type of the first procedure (ETV or VPS placement). When an ETV was performed, we noted the result (success, redo, or shunt insertion). When a shunt was inserted, we noted the shunt type as either a VPS or ventriculoatrial shunt (VAS), the valve type as either a flow-controlled (Orbis-Sigma valve [OSV]) or differential-pressure (DP) valve (either a Hakim pediatric medium-pressure valve or a Delta valve [diaphragm medium-pressure valve with an antisiphon device]), the side of the ventricular catheter, and the position of the ventricular catheter as either correct (with the ventricular tip within the ventricle and not contacting the choroid plexus or the ependyma) or questionable. The position of the tip of the ventricular catheter was judged on the first postoperative MR or CT image. Neuroradiologists reviewed these studies, taking into account the position of the last $2 \mathrm{~cm}$ of the ventricular catheter.

If shunt revision occurred, we noted the timing and the cause (mechanical or infection). Mechanical complications were divided into obstruction (ventricular catheter, valve, peritoneal catheter), fracture/disconnection (proximal, distal), migration, improper placement, overdrainage (proximal obstruction related to slit ventricles, isolated ventricles, subdural hematoma), miscellaneous (lengthening procedure, others), and no evidence of malfunction when testing the system during the revision surgery. We also noted the type and total number of shunt revisions for each patient.

\section{Statistical Analysis}

We used SSPS version 20 (IBM Corp.) for statistical analyses. Because the cohort was large, we assumed the normality of the distribution. Parametric tests for descriptive analyses were used with a $95 \%$ confidence interval. The different groups of patients were statistically evaluated using a log-rank test, and a $\mathrm{p}$ value $<0.05$ was considered significant. Kaplan-Meier survival curves were performed for the time to failure of a procedure. Time to shunt failure was compared between the groups by using a log-rank test. A Cox proportional-hazards regression was used to perform multivariate analyses.

\section{Results \\ Overall Study Population}

Between 1985 and 1995, 975 children under 18 years of age were treated for hydrocephalus at our institution. There was a slight preponderance of boys $(54.6 \%$; Table 1). The median age at first surgery was 195 days (mean 3.2 years). The mean follow-up was $11 \pm 7.4$ years (mean \pm standard deviation) with a maximum of 28 years. Seventy percent had a follow-up $\geq 5$ years and $60 \%$ had a follow-up $\geq 10$ years. With respect to etiologies of the hydrocephalus, the most common cause was tumor related (32.3\%), followed by malformative (24.5\%) and inflammatory $(20.9 \%)$ causes. The gestational age at birth was available in 694 patients, and $30.5 \%$ of these children were born preterm. Overall mortality was $16.5 \%$; mortality due to tumor progression was $12.5 \%$. The mortality rate due to the hydrocephalus itself was $1 \%$. In 695 patients, the hydrocephalus was initially managed with shunt insertion, whereas the remaining 280 patients underwent ETV.

\section{ETV Group}

In 280 patients with an obstruction at the level of the posterior fossa or in whom aqueductal stenosis was suspected, ETV was performed as the first-line treatment (Table 2). The sex ratio showed a male predominance (52.5\%). The main etiology was posterior fossa tumor-related hydrocephalus (155 patients). The ETV was successful in 204 cases $(72.8 \%)$, needed to be redone in 8 cases $(2.8 \%)$, or was unsuccessful and required shunt implantation in 68 cases $(24.3 \%)$. A Kaplan-Meier survival curve for the ETV population is shown in Fig. 1A. Survival analysis of ETV showed an overall survival of $76.9 \%$ at 1 year and $70 \%$ at 10 and 20 years. With respect to ETV and etiology, ETV is effective in controlling hydrocephalus due to posterior fossa tumors and aqueductal stenosis. It was much less effective for hydrocephalus due to intraventricular hemorrhage or infection ( $<<0.001$; Fig. 1B). 
TABLE 1. Summary of characteristics of the entire pediatric population with an initial presentation for hydrocephalus at Hôpital Necker-Enfants Malades between 1985 and 1995

\begin{tabular}{|c|c|}
\hline Variable & No. $(\%)$ \\
\hline Total & 975 \\
\hline \multicolumn{2}{|l|}{ Sex } \\
\hline M & $532(54.6)$ \\
\hline $\mathrm{F}$ & $443(45.4)$ \\
\hline \multicolumn{2}{|l|}{ Age at $1 \mathrm{st}$ treatment in yrs } \\
\hline Mean & $3.2 \pm 4.5$ \\
\hline Max & 17.6 \\
\hline Min & 0 \\
\hline Median age at 1 st surgery in days & 195 \\
\hline Mean follow-up in yrs & $11 \pm 7.4$ \\
\hline Patients w/ term of pregnancy data & $694(71.2)$ \\
\hline Preterm patients & $212(30.5)$ \\
\hline \multicolumn{2}{|l|}{ Type of treatment } \\
\hline Shunt & $695(71.3)$ \\
\hline ETV & $280(28.7)$ \\
\hline \multicolumn{2}{|l|}{ Etiology } \\
\hline Inflammation & $204(20.9)$ \\
\hline Malformation & $239(24.5)$ \\
\hline Aqueductal stenosis & $77(7.9)$ \\
\hline Tumor & $315(32.3)$ \\
\hline Other & $140(14.4)$ \\
\hline \multicolumn{2}{|l|}{ Death } \\
\hline Yes & $161(16.5)$ \\
\hline No & $814(83.5)$ \\
\hline
\end{tabular}

Mean values expressed with standard deviations.

\section{Shunt Group}

\section{Overall Shunt Cohort}

Over the 10-year study period, 695 children had initial shunt insertion. Most of the children were under the age of 1 year at the time of the first shunt implantation $(69.2 \%$; Table 3). The median age at first surgery was 127.5 days, and the mean age was $2.1 \pm 3.8$ years. The mean followup was $12.5 \pm 7.6$ years. The two main etiologies were malformative (29.9\%) and inflammatory (27.3\%) hydrocephalus.

Valve choice was based on surgeon preference. The majority of patients had an OSV (635 patients), and the VPS was largely preferred for the first procedure (693 patients). The side of ventricular catheter insertion was preferably the larger one, and the right side was chosen in 603 cases. The ventricular catheter was correctly positioned in the majority of cases (600 patients).

Of the 695 children who had initial shunt insertion, 271 had at least one mechanical failure and 72 had at least one shunt infection (Table 4). A total of 1234 shunt procedures were performed, and 456 were shunt revisions for mechanical failure in 271 patients and 83 revisions for infection in 72 patients. The mean number of revisions for a mechanical shunt malfunction was $0.66 \pm 1.1$. The global rate of shunt infection in this series was $6.7 \%$.
TABLE 2. Characteristics of the pediatric population treated with ETV at Hôpital Necker-Enfants Malades

\begin{tabular}{cc}
\hline \multicolumn{1}{c}{ Variable } & No. $(\%)$ \\
\hline Total & 280 \\
\hline Sex & $147(52.5)$ \\
\hline M & $133(47.5)$ \\
\hline Age at 1st treatment in yrs & $5.8 \pm 5.2$ \\
\hline Mean & 17.6 \\
\hline Max & 0 \\
\hline Min & 5.1 \\
\hline Median age at 1st surgery in yrs & $4.3 \pm 5$ \\
\hline Mean follow-up in yrs & $14(5.0)$ \\
\hline Etiology & $31(11.1)$ \\
\hline Inflammation & $61(21.8)$ \\
\hline Malformation & $155(55.4)$ \\
\hline Aqueductal stenosis & $19(6.8)$ \\
\hline Tumor & \\
\hline Other & $204(72.8)$ \\
\hline ETV outcome & $68(24.3)$ \\
\hline Success & $8(2.8)$ \\
\hline Shunt insertion &
\end{tabular}

The maximum number of mechanical shunt failures was 8. Most of the patients whose shunts failed for mechanical reasons experienced only one shunt failure (176 patients). The number of shunt revisions for infection and mechanical failure is shown in Table 4. Reasons for mechanical failure of the first shunt are detailed in Table 5, and a Kaplan-Meier survival curve is presented in Fig. 2. On univariate analyses, patient sex, gestational age at birth, and age at the first shunt implantation (age $<1$ year or $\geq 1$ year) were not significantly associated with shunt failure ( $\mathrm{p}=0.3,0.6$, and 0.1 , respectively). However, the position of the ventricular catheter was significantly associated with better shunt survival when the catheter was correctly placed $(\mathrm{p}<0.001)$. Multivariate analyses revealed that only the position of the ventricular catheter was significantly associated with a worse shunt survival when the catheter was incorrectly placed (HR 2.01, 95\% CI 1.44-2.82).

\section{Differential-Pressure Valve Group}

Sixty patients initially received a DP shunt because of surgeon preference. The epidemiological characteristics and causes of hydrocephalus in this group are reported in Table 6. Survival analysis (Fig. 3) showed an overall shunt survival of $60 \%$ at 1 year, $37 \%$ at 10 years, and $29 \%$ at 20 years.

\section{Orbis-Sigma Valve Group}

The majority of our population (635 patients) received an OSV as the first shunt. The epidemiological characteristics and causes of hydrocephalus in this group are reported in Table 6. Survival analysis (Fig. 3) showed 

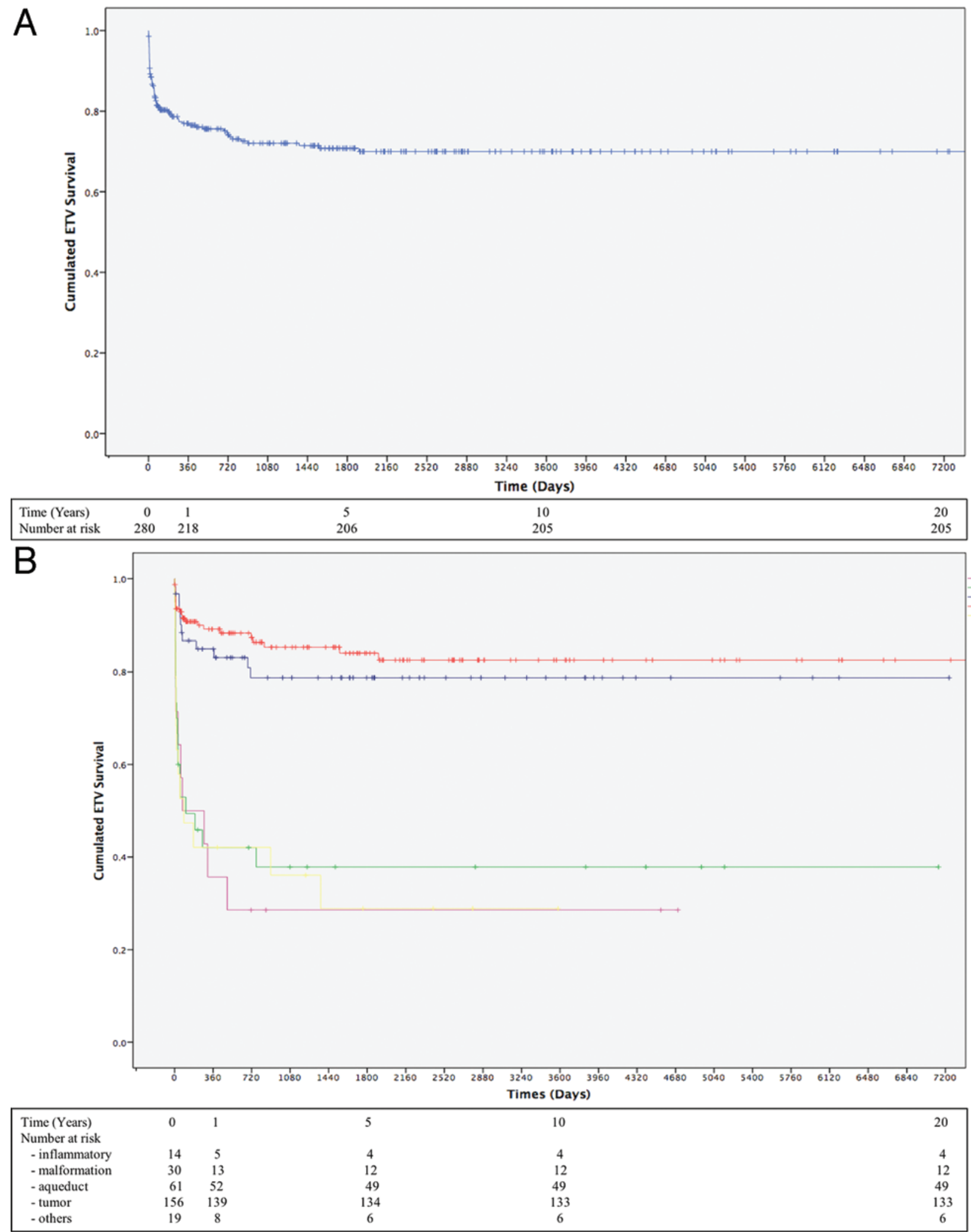

FIG. 1. A: Kaplan-Meier survival curve showing overall survival for the ETV population at Hôpital Necker-Enfants Malades. B: Kaplan-Meier survival curve for the ETV population according to hydrocephalus etiology. Numbers at the bottom indicate the number of patients at risk. Figure is available in color online only. 
TABLE 3. Characteristics of the pediatric population treated with a shunt at Hôpital Necker-Enfants Malades

\begin{tabular}{|c|c|}
\hline Variable & №. $(\%)$ \\
\hline Total & 695 \\
\hline \multicolumn{2}{|l|}{ Sex } \\
\hline$M$ & $385(55.4)$ \\
\hline $\mathrm{F}$ & $310(44.6)$ \\
\hline \multicolumn{2}{|l|}{ Age at 1 st treatment in yrs } \\
\hline Mean & $2.1 \pm 3.8$ \\
\hline Max & 13.5 \\
\hline Min & 0 \\
\hline Median age at 1st surgery in days & 127 \\
\hline \multicolumn{2}{|l|}{ Age } \\
\hline$<1 \mathrm{yr}$ & $481(69.2)$ \\
\hline$\geq 1 \mathrm{yr}$ & $214(30.8)$ \\
\hline Mean follow-up in yrs & $12.5 \pm 7.6$ \\
\hline \multicolumn{2}{|l|}{ Etiology } \\
\hline Inflammation & $190(27.3)$ \\
\hline Malformation & $208(29.9)$ \\
\hline Aqueductal stenosis & $16(2.3)$ \\
\hline Tumor & $160(23.0)$ \\
\hline Other & $121(17.4)$ \\
\hline \multicolumn{2}{|l|}{ Shunt type } \\
\hline VPS & $693(99.7)$ \\
\hline VAS & $2(0.3)$ \\
\hline \multicolumn{2}{|l|}{ Valve type } \\
\hline OSV & $635(91.4)$ \\
\hline $\mathrm{DP}$ & $60(8.6)$ \\
\hline \multicolumn{2}{|l|}{ Ventricular catheter insertion side } \\
\hline $\mathrm{Rt}$ & $603(86.8)$ \\
\hline Lt & $92(13.2)$ \\
\hline \multicolumn{2}{|l|}{ Ventricular catheter position } \\
\hline Correct & $600(86.3)$ \\
\hline Questionable & $95(13.7)$ \\
\hline
\end{tabular}

an overall shunt survival of $70 \%$ at 1 year, $58 \%$ at 10 years, and $49 \%$ at 20 years. The most common cause of mechanical shunt failure was obstruction $(50.7 \%$; Table $7)$. There was a significant difference $(p=0.04)$ in shunt survival according to the etiology of the hydrocephalus (Fig. 4).

\section{Comparison Between the DP and OSV Shunt Groups}

Although comparison of the OSV and DP shunt groups is interesting, we are aware that the number of DP shunts is small as compared with OSV numbers and is confounded by surgeon preference. Therefore, results must be interpreted in light of these limitations. The DP shunts were used by surgeons who had joined the neurosurgical team during the studied period and were allowed to use the DP shunts with which they were familiar.

There were no statistical differences between the DP and OSV shunt groups with respect to sex $(p=0.2)$, age at the first treatment $(\mathrm{p}=0.5)$, gestational age at birth $(\mathrm{p}=$ $0.5)$, and etiology of the hydrocephalus ( $\mathrm{p}=0.08$; Table 6 ).
TABLE 4. Shunt revisions per patient for infection and mechanical failure

\begin{tabular}{cc}
\hline \multicolumn{1}{c}{ Shunt Revisions } & No. of Patients $(\%)$ \\
\hline Due to infection & \\
\hline 0 & $623(89.6)$ \\
\hline 1 & $63(9.1)$ \\
\hline 2 & $8(1.2)$ \\
\hline 3 & $0(0)$ \\
\hline 4 & $1(0.1)$ \\
\hline Due to mechanical failure & \\
\hline 0 & $424(61.0)$ \\
\hline 1 & $176(25.3)$ \\
\hline 2 & $49(7.0)$ \\
\hline 3 & $25(3.6)$ \\
\hline 4 & $11(1.6)$ \\
\hline 5 & $3(0.4)$ \\
\hline 6 & $4(0.6)$ \\
\hline 7 & $0(0)$ \\
\hline 8 & $3(0.4)$ \\
\hline
\end{tabular}

Overall shunt survival was statistically different between the two valve designs ( $p=0.009$; Fig. 3). Multivariate analyses, adjusting for sex, gestational age at birth, and age at the first shunt implantation (age $<1$ year or $\geq$ 1 year), revealed that DP shunts were associated with significant worse shunt survival than OSV shunts (HR 1.77, 95\% CI 1.19-2.64). With respect to the etiology of mechanical shunt dysfunction (Fig. 5), there was no significant difference between the two valve systems except for shunt dysfunction due to chronic overdrainage $(\mathrm{p}=0.007)$. Moreover, the time to onset of dysfunction was widely variable regardless of valve type; for example, ventricular catheter obstruction occurred much later in the OSV group, whereas valve obstruction occurred earlier.

\section{Discussion}

Improvement in the management of hydrocephalus is one of the many goals of the pediatric neurosurgeon. Despite the development of CSF diversion mechanisms from

TABLE 5. Mechanical complications associated with shunt revision

\begin{tabular}{cc}
\hline Etiology of Mechanical Failure & No. of Patients (\%) \\
\hline Obstruction & $127(46.9)$ \\
\hline Valve & $49(18.1)$ \\
\hline Ventricular catheter & $73(26.9)$ \\
\hline Peritoneal catheter & $5(1.8)$ \\
\hline Fracture & $32(11.8)$ \\
\hline Migration & $38(14.0)$ \\
\hline Improper placement & $22(8.1)$ \\
\hline Overdrainage & $17(6.3)$ \\
\hline Miscellaneous & $11(4.0)$ \\
\hline No evidence of malfunction & $24(8.8)$ \\
\hline
\end{tabular}




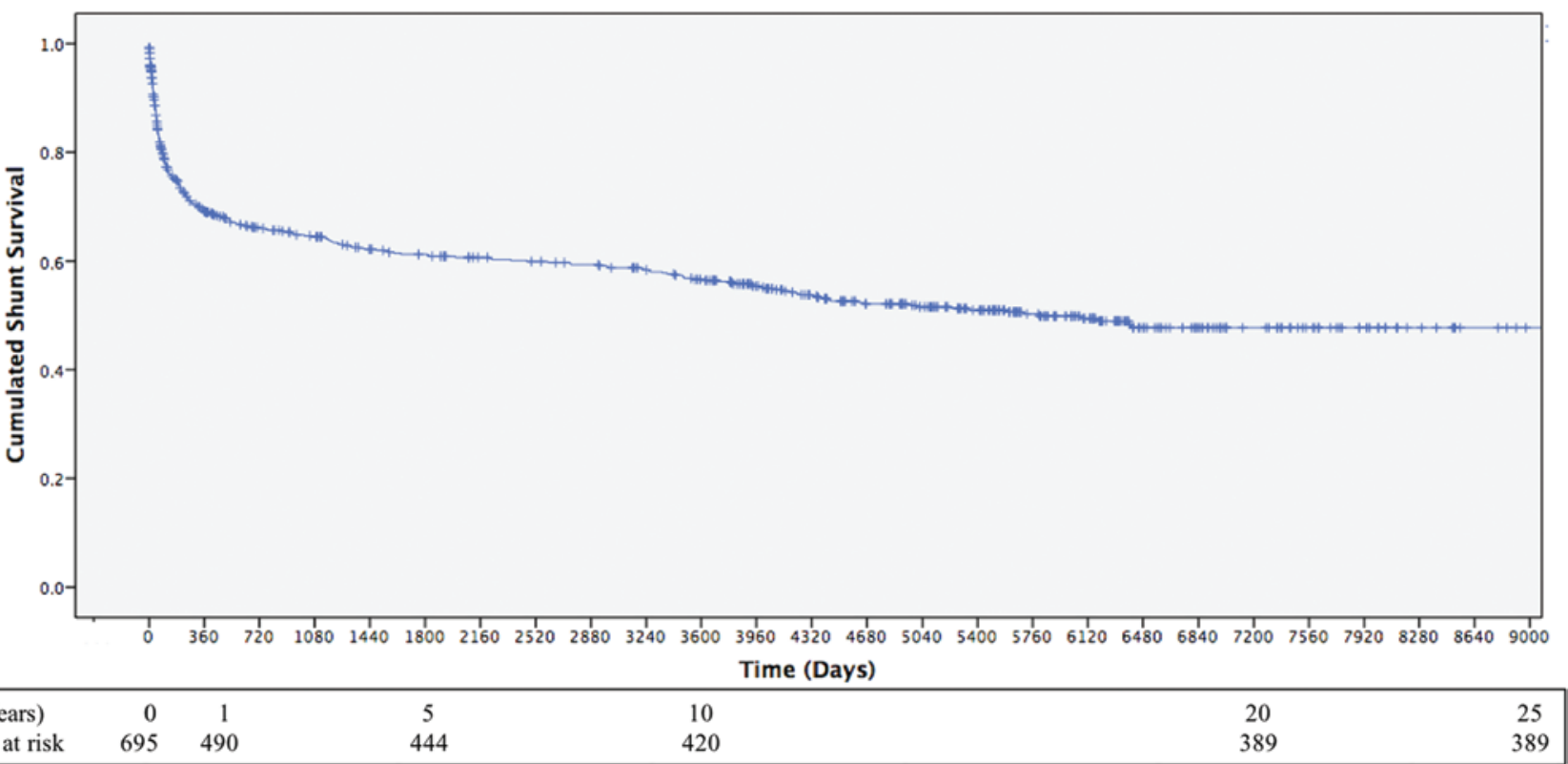

FIG. 2. Kaplan-Meier curve showing overall shunt survival in the pediatric population at Hôpital Necker-Enfants Malades. Numbers at the bottom indicate the number of patients at risk. Figure is available in color online only.

as early as the $1950 \mathrm{~s},{ }^{17}$ shunt diversion systems remain associated with multiple complications. ${ }^{27}$ Thus, when ETV entered the neurosurgical arena, it rapidly gained acceptance in the treatment of hydrocephalus. ${ }^{13}$ While ETV was initially confined to the management of aqueductal stenosis-induced hydrocephalus, its indications rapidly expanded to include hydrocephalus due to other etiologies. ${ }^{1,28,30}$ Our results in the ETV group parallel those reported in the literature with excellent success overall but highly dependent on etiology. Specifically, success is low in the inflammatory etiologies such as postinfectious or

TABLE 6. Characteristics of the population treated with a DP shunt or an OSV shunt at the Hôpital Necker-Enfants Malades

\begin{tabular}{|c|c|c|c|}
\hline \multirow[b]{2}{*}{ Variable } & \multicolumn{2}{|c|}{ No. $(\%)$} & \multirow{2}{*}{$\begin{array}{c}p \\
\text { Value }\end{array}$} \\
\hline & DP Shunt & OSV Shunt & \\
\hline Total & 60 & 635 & \\
\hline Sex & & & 0.2 \\
\hline M & $29(48.3)$ & $356(56.1)$ & \\
\hline $\mathrm{F}$ & $31(51.7)$ & $279(43.9)$ & \\
\hline Age at 1st treatment & & & 0.5 \\
\hline Mean (yrs) & $2.2 \pm 3.8$ & $2.1 \pm 3.8$ & \\
\hline $\operatorname{Max}(y r s)$ & 15.7 & 17.3 & \\
\hline Min (days) & 5 & 0 & \\
\hline Median age at 1st treatment in days & 101.5 & 127 & 0.5 \\
\hline Etiology & & & 0.08 \\
\hline Inflammation & $22(36.7)$ & $168(26.4)$ & \\
\hline Malformation & $18(30.0)$ & $190(29.9)$ & \\
\hline Aqueductal stenosis & $2(3.3)$ & $14(2.2)$ & \\
\hline Tumor & $15(25.0)$ & $145(22.8)$ & \\
\hline Other & $3(5.0)$ & $118(18.6)$ & \\
\hline
\end{tabular}

posthemorrhagic hydrocephalus and high in congenital or acquired aqueductal stenosis., ${ }^{4,16}$

Since their initial development, ${ }^{26}$ shunt valve systems have undergone many iterations aimed at lowering complications and decreasing the number of shunt revisions. In the Hôpital Necker-Enfants Malades, the OSV, a flow-regulated valve developed by the senior author (C.S.R.) to minimize overdrainage and related complications, ${ }^{21}$ has been used almost exclusively since the 1980s. However, despite a European survey reporting a 5-year shunt failure-free interval in $62 \%$ of cases and a $1.8 \%$ rate of overdrainage, ${ }^{8}$ the valve had not been conclusively shown to have a design that was superior to another., ${ }^{5,11}$ With previously published reports of shunt survival ${ }^{5,7,8,10-12,14,15,18-20,22-25,31}$ constrained by limited patient numbers and short follow-up periods, it has been difficult to draw meaningful conclusions.

The present study is one of the largest on treated childhood hydrocephalus and has one of the longest follow-up

TABLE 7. Details of mechanical shunt complications in the OSV shunt population

\begin{tabular}{cc}
\hline Cause of Mechanical Failure & No. of Patients $(\%)$ \\
\hline Obstruction & $113(50.7)$ \\
\hline Ventricular catheter & $64(28.7)$ \\
\hline Valve & $46(20.6)$ \\
\hline Peritoneal catheter & $3(1.3)$ \\
\hline Fracture & $22(9.9)$ \\
\hline Migration & $32(14.3)$ \\
\hline Improper placement & $20(9)$ \\
\hline Overdrainage & $10(4.5)$ \\
\hline Miscellaneous & $8(3.6)$ \\
\hline No evidence of malfunction & $18(8.1)$ \\
\hline
\end{tabular}




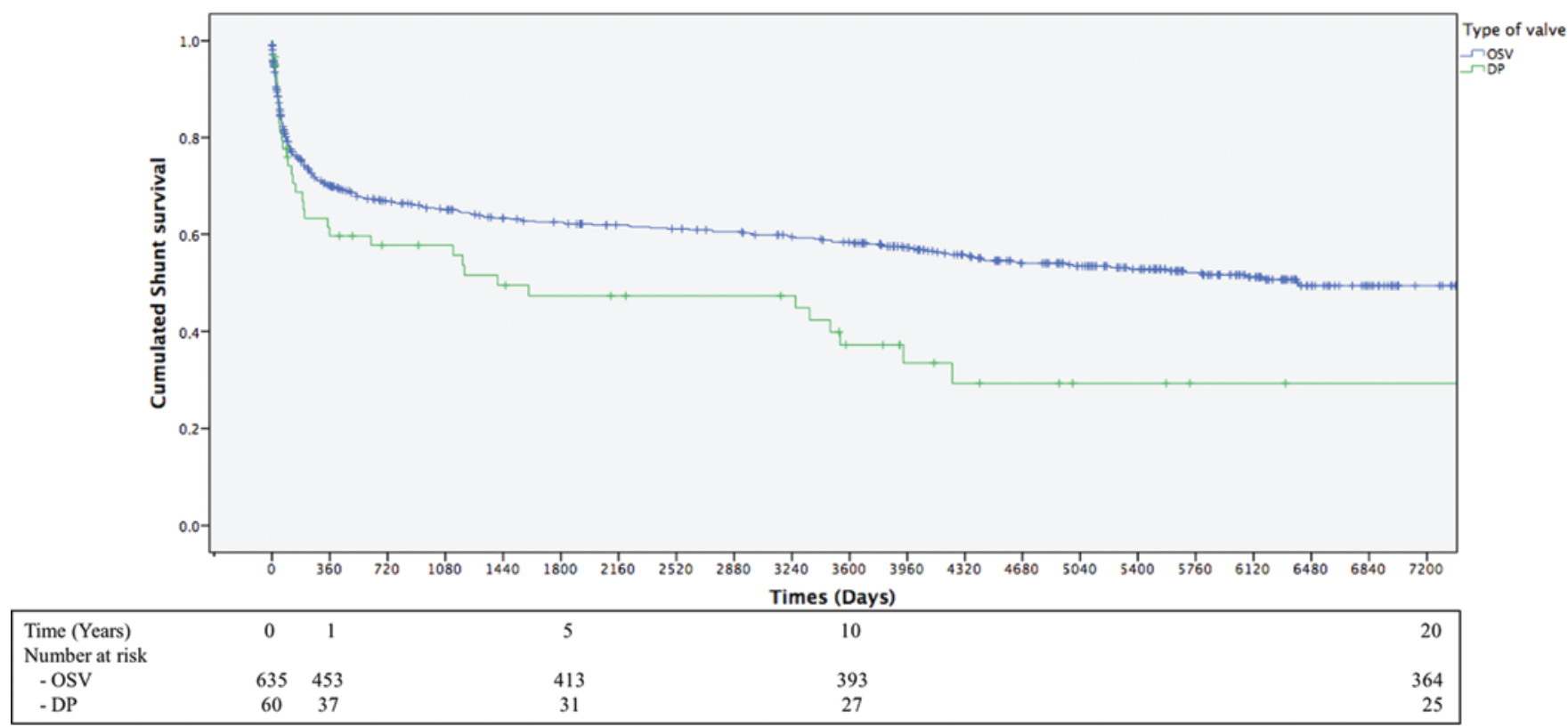

FIG. 3. Kaplan-Meier curve showing overall shunt survival in the different valve groups at the Hôpital Necker-Enfants Malades. Numbers at the bottom indicate the number of patients at risk. Figure is available in color online only.

periods (mean 11 years, maximum 28 years). It is the first to report a significant difference in favor of the OSV shunt with respect to long-term shunt survival $(p=0.009)$. Furthermore, complications related to overdrainage (that is, "delayed" ventricular catheter obstruction) were significantly less frequent $(\mathrm{p}=0.007)$, although valve obstruction occurred earlier ( $<1$ year postimplantation) than in the DP shunt group (more tolerant to debris in the CSF).

The OSV shunt was specifically designed to obtain this result. It accomplishes this by setting the drainage flow rate to $20-25 \mathrm{ml} /$ hour, approximating the mean rate of CSF secretion..$^{21}$ It is obvious that in many children, this

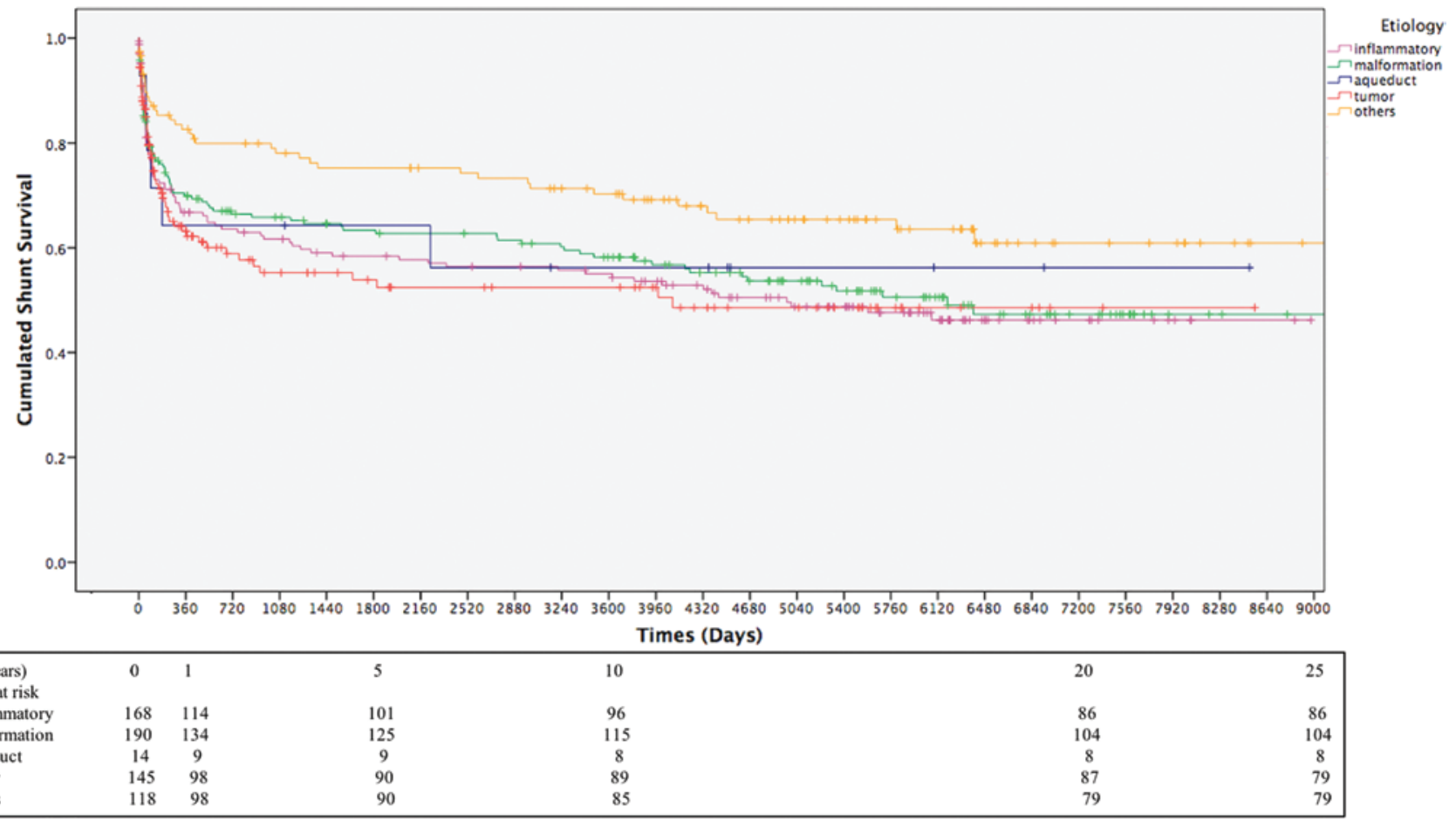

FIG. 4. Kaplan-Meier curve showing shunt survival according to hydrocephalus etiology in the pediatric population treated with an OSV shunt. Numbers at the bottom indicate the number of patients at risk. Figure is available in color online only. 


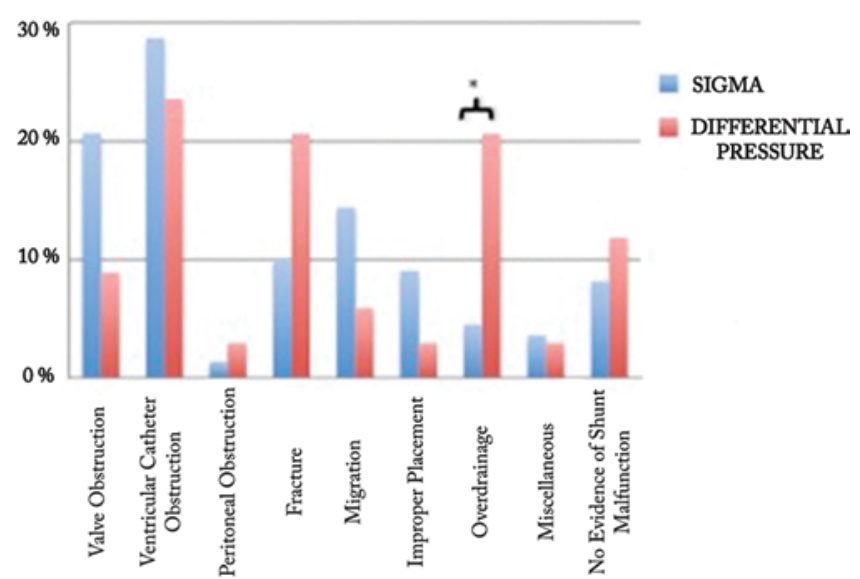

FIG. 5. Origin of shunt failure. ${ }^{*} p<0.05$. Figure is available in color online only.

flow rate would be greater than the drainage requirements. Therefore, not surprisingly, overdrainage still represented $4.5 \%$ of all complications in the OSV group in our series. However, this rate is 50 times smaller than what occurs with DP valves. ${ }^{21}$

In analyzing the different shunt survival curves across different series, including our own, one feature remains striking-the similar pattern of shunt failure regardless of valve type. There is an initial high incidence of failure or infection during the first few months following shunt implantation, ${ }^{5}$ mainly related to surgical complications (improper placement, questionable ventricular catheter tip location, disconnection, and so forth) rather than valve design. In our study, $13.7 \%$ of the ventricular catheters were in a "questionable" position and accounted for $8 \%$ of all shunt complications. In addition, we found that the position of the ventricular catheter was significantly associated with better shunt survival when the catheter was correctly placed ( $\mathrm{p}<0.001)$. Improper placement might be avoided by using stereotactic or ultrasonography-guided techniques. ${ }^{29}$

Valve design contributes to "late" complications (for example, proximal obstruction favored by small ventricles induced by chronic overdrainage). In our study, the 50\% rate of shunt survival was reached at almost 18 years in the OSV group, in stark comparison with 3.5 years in the DP group.

As stated above, this study has one of the longest follow-up periods in a pediatric population with hydrocephalus. The actuarial curve demonstrated a high long-term shunt survival rate (49\% at 20 years). Such a rate has not been previously achieved, with average event-free shunt survival in the literature approximating $40 \%$ at 10 years. ${ }^{27}$ Paulsen et al. reported a much higher rate of shunt revision $(81 \%)$ over a 20 -year period. ${ }^{19}$

\section{Conclusions}

This large series of pediatric patients consecutively treated for hydrocephalus with a long-term follow-up has demonstrated several clear findings. Firstly, ETV is an effective tool in the management of childhood hydrocephalus. Its success, however, is directly related to the underlying causative pathology. The impact of patient selection must be taken into account when analyzing results of this technique. Secondly, drainage flow rate control (OSV), in the long term, has significantly higher event-free shunt survival than the classic pressure control (DP valve systems without and with add-ons) with a significantly lower rate of chronic overdrainage (very small ventricles) and subsequent proximal obstructions.

Nonetheless, two remarks must be kept in mind. 1) This is a single-center retrospective study, and a Class I trial is needed to confirm our results. 2) This is a pediatric study, and the results must be verified in the adult population, in which the patterns of shunt dysfunction are not exactly the same.

\section{Acknowledgments}

We gratefully acknowledge Dr. Wirginia Maixner for her contribution to the editing and reviewing of the manuscript.

\section{References}

1. Beuriat PA, Szathmari A, Grassiot B, Plaisant F, Rousselle C, Mottolese C: Role of endoscopic third ventriculostomy in the management of myelomeningocele related hydrocephalus: a retrospective study in a single French institution. World Neurosurg 87:484-493, 2016

2. Chari A, Czosnyka M, Richards HK, Pickard JD, Czosnyka $\mathrm{ZH}$ : Hydrocephalus shunt technology: 20 years of experience from the Cambridge Shunt Evaluation Laboratory. J Neurosurg 120:697-707, 2014

3. Cochrane DD, Kestle JRW: The influence of surgical operative experience on the duration of first ventriculoperitoneal shunt function and infection. Pediatr Neurosurg 38:295301, 2003

4. Di Rocco F, Jucá CE, Zerah M, Sainte-Rose C: Endoscopic third ventriculostomy and posterior fossa tumors. World Neurosurg 79 (2 Suppl):S18.e15-S18.e19, 2013

5. Drake JM, Kestle JRW, Milner R, Cinalli G, Boop F, Piatt J $\mathrm{Jr}$, et al: Randomized trial of cerebrospinal fluid shunt valve design in pediatric hydrocephalus. Neurosurgery 43:294305, 1998

6. Drake JM, Kestle JRW, Tuli S: CSF shunts 50 years on-past, present and future. Childs Nerv Syst 16:800-804, 2000

7. Haberl EJ, Messing-Juenger M, Schuhmann M, Eymann R, Cedzich C, Fritsch MJ, et al: Experiences with a gravityassisted valve in hydrocephalic children. Clinical article. J Neurosurg Pediatr 4:289-294, 2009

8. Hanlo PW, Cinalli G, Vandertop WP, Faber JAJ, Bøgeskov L, Børgesen SE, et al: Treatment of hydrocephalus determined by the European Orbis Sigma Valve II survey: a multicenter prospective 5-year shunt survival study in children and adults in whom a flow-regulating shunt was used. J Neurosurg 99:52-57, 2003

9. Kahle KT, Kulkarni AV, Limbrick DD Jr, Warf BC: Hydrocephalus in children. Lancet 387:788-789, 2016

10. Kehler U, Kiefer M, Eymann R, Wagner W, Tschan CA, Langer N, et al: PROSAIKA: a prospective multicenter registry with the first programmable gravitational device for hydrocephalus shunting. Clin Neurol Neurosurg 137:132-136, 2015

11. Kestle J, Drake J, Milner R, Sainte-Rose C, Cinalli G, Boop F, et al: Long-term follow-up data from the shunt design trial. Pediatr Neurosurg 33:230-236, 2000

12. Kestle JRW, Walker ML: A multicenter prospective cohort study of the Strata valve for the management of hydrocephalus in pediatric patients. J Neurosurg 102 (2 Suppl):141-145, 2005

13. Kulkarni AV, Riva-Cambrin J, Browd SR, Drake JM, Holub- 
kov R, Kestle JRW, et al: Endoscopic third ventriculostomy and choroid plexus cauterization in infants with hydrocephalus: a retrospective Hydrocephalus Clinical Research Network study. J Neurosurg Pediatr 14:224-229, 2014

14. Kulkarni AV, Riva-Cambrin J, Butler J, Browd SR, Drake JM, Holubkov R, et al: Outcomes of CSF shunting in children: comparison of Hydrocephalus Clinical Research Network cohort with historical controls: clinical article. J Neurosurg Pediatr 12:334-338, 2013

15. McGirt MJ, Leveque JC, Wellons JC III, Villavicencio AT, Hopkins JS, Fuchs HE, et al: Cerebrospinal fluid shunt survival and etiology of failures: a seven-year institutional experience. Pediatr Neurosurg 36:248-255, 2002

16. Mugamba J, Stagno V: Indication for endoscopic third ventriculostomy. World Neurosurg 79 (2 Suppl):S20.e19-S20. e23, 2013

17. Nulsen FE, Spitz EB: Treatment of hydrocephalus by direct shunt from ventricle to jugular vein. Surg Forum 1951:399403, 1951

18. Paulsen AH, Lundar T, Lindegaard KF: Pediatric hydrocephalus: 40-year outcomes in 128 hydrocephalic patients treated with shunts during childhood. Assessment of surgical outcome, work participation, and health-related quality of life. J Neurosurg Pediatr 16:633-641, 2015

19. Paulsen AH, Lundar T, Lindegaard KF: Twenty-year outcome in young adults with childhood hydrocephalus: assessment of surgical outcome, work participation, and health-related quality of life. J Neurosurg Pediatr 6:527-535, 2010

20. Reddy GK, Bollam P, Caldito G: Long-term outcomes of ventriculoperitoneal shunt surgery in patients with hydrocephalus. World Neurosurg 81:404-410, 2014

21. Sainte-Rose C, Hooven MD, Hirsch JF: A new approach in the treatment of hydrocephalus. J Neurosurg 66:213-226, 1987

22. Shah SS, Hall M, Slonim AD, Hornig GW, Berry JG, Sharma V: A multicenter study of factors influencing cerebrospinal fluid shunt survival in infants and children. Neurosurgery 62:1095-1103, 2008

23. Shannon CN, Acakpo-Satchivi L, Kirby RS, Franklin FA, Wellons JC: Ventriculoperitoneal shunt failure: an institutional review of 2-year survival rates. Childs Nerv Syst 28:2093-2099, 2012

24. Shannon CN, Carr KR, Tomycz L, Wellons JC, Tulipan $\mathrm{N}$ : Time to first shunt failure in pediatric patients over 1 year old: a 10 -year retrospective study. Pediatr Neurosurg 49:353-359, 2013

25. Stone JJ, Walker CT, Jacobson M, Phillips V, Silberstein HJ: Revision rate of pediatric ventriculoperitoneal shunts after 15 years. J Neurosurg Pediatr 11:15-19, 2013
26. Symss NP, Oi S: Is there an ideal shunt? A panoramic view of 110 years in CSF diversions and shunt systems used for the treatment of hydrocephalus: from historical events to current trends. Childs Nerv Syst 31:191-202, 2015

27. Vinchon M, Rekate H, Kulkarni AV: Pediatric hydrocephalus outcomes: a review. Fluids Barriers CNS 9:18, 2012

28. Warf BC: Comparison of endoscopic third ventriculostomy alone and combined with choroid plexus cauterization in infants younger than 1 year of age: a prospective study in 550 African children. J Neurosurg 103 (6 Suppl):475-481, 2005

29. Wilson TJ, Stetler WR Jr, Al-Holou WN, Sullivan SE: Comparison of the accuracy of ventricular catheter placement using freehand placement, ultrasonic guidance, and stereotactic neuronavigation. J Neurosurg 119:66-70, 2013

30. Zandian A, Haffner M, Johnson J, Rozzelle CJ, Tubbs RS, Loukas M: Endoscopic third ventriculostomy with/without choroid plexus cauterization for hydrocephalus due to hemorrhage, infection, Dandy-Walker malformation, and neural tube defect: a meta-analysis. Childs Nerv Syst 30:571-578, 2014

31. Zemack G, Romner B: Seven years of clinical experience with the programmable Codman Hakim valve: a retrospective study of 583 patients. J Neurosurg 92:941-948, 2000

\section{Disclosures}

Dr. Sainte-Rose co-developed with the Cordis Company one of the valves used in this study (Orbis-Sigma valve). This collaboration was initiated in 1985, extended to the Integra Company after its purchase of this activity, and was stopped several years ago. There is no ongoing financial conflict of interest of any kind.

\section{Author Contributions}

Conception and design: Beuriat, Sainte-Rose. Acquisition of data: Beuriat. Analysis and interpretation of data: Beuriat, Sainte-Rose. Drafting the article: Beuriat. Critically revising the article: Puget, Cinalli, Blauwblomme, Beccaria, Zerah, Sainte-Rose. Reviewed submitted version of manuscript: Sainte-Rose. Approved the final version of the manuscript on behalf of all authors: Beuriat. Statistical analysis: Beuriat, Sainte-Rose. Study supervision: SainteRose.

\section{Correspondence}

Pierre-Aurelien Beuriat, Department of Pediatric Neurosurgery, Hôpital Femme Mère Enfant, 32 Ave. du Doyen Jean Lépine, Lyon 69677, France. email: pierre-aurelien.beuriat@neurochirurgie.fr. 